\title{
INEQUALITIES DESCRIBING THE GROWTH OF POLYNOMIALS NOT VANISHING IN A DISK OF PRESCRIBED RADIUS
}

\author{
N. K. GOVIL, M. A. QAZI AND Q. I. RAHMAN
}

Abstract. In this paper we study the growth of polynomials of degree $n$ having no zeros in $|z|<\kappa$, where $\kappa$ is an arbitrary positive number. Using the notation $M(p ; t)=\max _{|z|=t}|p(z)|$ we measure the growth of $p$ by estimating $M(p ; t) / M(p ; 1)$ from above for any $t>1$, and from below for any $t<1$.

Mathematics subject classification (2000): 30A10, 30C10, 30E10; 30C15.

Key words and phrases: Polynomials, restricted zeros, growth, inequalities.

\section{REFERENCES}

[1] N. C. Ankeny And T. J. Rivlin, On a theorem of S. Bernstein, Pacific J. Math. 5 (1955), 849-852.

[2] S. N. Bernstein, Sur la limitation des dérivées des polynômes, C. R. Acad. Sci. Paris 190 (1930), 338-341.

[3] R. P. BOAS, JR., Entire Functions, Academic Press, New York, 1954.

[4] R. P. BOAS, JR., Inequalities for asymmetric entire functions, Illinois J. Math. 1 (1957), 94-97.

[5] R. P. BOAS, JR., AND Q. I. RAHMAN, Some inequalities for polynomials and entire functions, Doklady Akad. Nauk. SSSR 147 (1962), 11-12 (Russian).

[6] R. P. BOAS, JR., AND Q. I. RAHMAN, $L^{p}$ inequalities for polynomials and entire functions, Arch. Rational Mech. Anal. 11 (1962), 34-39.

[7] N. K. GovIL AND Q. I. RAHMAN, Functions of exponential type not vanishing in a half-plane and related polynomials, Trans. Amer. Math. Soc. 137 (1969), 501-517.

[8] V. K. JAIN, Certain interesting implications of T. J. Rivlin's result on maximum modulus of a polynomial, Glasnik Mathematički 33 (53) (1998), 33-36.

[9] P. D. LAX, Proof of a conjecture of P. Erdös on the derivative of a polynomial, Bull. Amer. Math. Soc. 50 (1944), 509-513.

[10] M. A. MALIK, On the derivative of a polynomial, J. London Math. Soc. 1 (1969), 57-60.

[11] G. V. Milovanović, D. S. Mitrinović and Th. M. Rassias, "Topics in Polynomials: Extremal Problems, Inequalities, Zeros", World Scientific, Singapore, 1994.

[12] G. PólYA AND G. SzEGÖ, "Problems and Theorems in Analysis, Volume I", Springer-Verlag, Berlin Heidelberg, 1972.

[13] M. A. QAZI, On the maximum modulus of polynomials, Proc. Amer. Math. Soc. 115 (1992), 337-343.

[14] Q. I. RAHMAN AND G. Schmeisser, "Les inégalités de Markoff et de Bernstein", Les Presses de Univ. Montréal, Montréal, 1983.

[15] M. RIESZ, Eine trigonometrische interpolationsformel und einige Ungleichungen für Polynome, Jahresbericht der Deutschen Mathematiker-Vereinigung 23 (1914), 354-368.

[16] T. J. RivLin, On the maximum modulus of polynomials, Amer. Math. Monthly 67 (1960), 251-253.

[17] E. C. Titchmarsh, "The Theory of Functions", 2nd edition, Oxford University Press, 1939.

[18] R. S. VARGA, A comparison of the successive overrelaxation method and semi-iterative methods using Chebyshev polynomials, J. Soc. Indust. Appl. Math. 5 (1957), 39-46.

[19] C. VISSER, A simple proof of certain inequalities concerning polynomials, Koninkl. Ned. Akad. Wetenschap., Proc. 48 (1945), 276-281 [=Indag. Math. 7 (1945), 81-86]. 